\title{
DESONTOLOGIZAÇÃO DO SUJEITO GENERIFICADO E A METAFÍSICA DA SUBSTÂNCIA: DIÁLOGOS DE BUTLER COM NIETZSCHE
}

\author{
André Luiz dos Santos Paiva ${ }^{1}$ \\ Universidade Federal de Pernambuco (UFPE) \\ https://orcid.org/0000-0002-1887-9960 \\ E-mail: alz.paiva@gmail.com
}

\section{RESUMO:}

$\mathrm{O}$ artigo discute como a teoria de gênero de Judith Butler, principalmente a partir do que a autora denominou de metafísica da substância, opera uma desontologização das experiências de sexo-gênero. Para isso, expõe-se como Butler opera a desontologização do sujeito generificado, através de sua crítica feminista acerca da ideia de sujeito concebida a partir do marco da diferença sexual. Posteriormente, dedica-se ao que Butler denominou de "metafísica da substância", vista como o que sustenta, no marco do sistema de sexo-gênero binário, a ideia de diferença natural dos corpos, momento no qual a autora recorre à genealogia da moral realizada por Nietzsche para justificar sua genealogia do gênero e dos corpos, vislumbrando esses como indissociáveis, razão pela qual conclui que, à maneira do gênero, a produção dos corpos ocorre de forma performativa através de recitações contextualizadas que estabelecem os marcos de inteligibilidade humana, os quais são, por isso, passíveis de transformação.

PALAVRAS-CHAVE: Judith Butler; Friedrich Nietzsche; Corpo; Gênero; Performatividade.

\section{DESONTOLOGIZATION OF THE GENDERED SUBJECT AND THE SUBSTANCE METAPHYSICS: BUTLER'S DIALOGUES WITH NIETZSCHE}

\begin{abstract}
:
The article discusses how Judith Butler's theory of gender, mainly based on what the author called metaphysics of substance, operates a desontologization of sex-gender experiences. For this, it exposes how Butler operates the desontologization of the gendered subject, through her feminist critique of the idea of subject conceived from the mark of sexual difference. Later, it dedicates to what Butler called the "metaphysics of substance", seen as what sustains, within the framework of the binary sex-gender system, the idea of natural difference of bodies, a moment in which the author resorts to the genealogy of morals developed by Nietzsche to justify her genealogy of gender and bodies, seeing these as inseparable, which is why she concludes that, in the manner of gender, the production of bodies occurs in a performative way through contextualized recitations that establish the boundaries of human intelligibility and that, therefore, it is subject to transformation.
\end{abstract}

KEYWORDS: Judith Butler; Friedrich Nietzsche; Body; Gender; Performativity.

\footnotetext{
1 Doutor(a) em Filosofia pela Universidade Federal do Rio Grande do Norte (UFRN), Natal - RN, Brasil. Bolsista do(a): Coordenação de Aperfeiçoamento de Pessoal de Nível Superior (CAPES), Brasil, de pós-doutorado no Programa de Pós-graduação em Educação Contemporânea (PPGEduc) da Universidade Federal de Pernambuco (UFPE), Caruaru - PE, Brasil.
}

PAIVA, André Luiz dos Santos. Desontologização do sujeito generificado e a metafísica da substância: diálogos de Butler com Nietzsche. Griot : Revista de Filosofia, Amargosa - BA, v.22 n.1, p.130-143, fevereiro, 2022. 


\section{Introdução: a desontologização do sujeito generificado}

É a partir da perspectiva performativa corporificada que se deve compreender a construção teórica de Butler acerca da fabricação dos gêneros. Antes de tudo, essa é uma concepção que desnaturaliza as experiências generificadas a partir de uma crítica interna ao conceito de gênero no âmbito dos movimentos feministas. Para Butler (1993, 1999), a apropriação desse conceito operava uma paradoxal naturalização das diferenças de gênero, constituindo-se como ferramenta que, ainda que explicitando o caráter social das experiências de gênero, acabava por reforçar a continuidade entre sexo, visto como natural, e gênero, concebido como categoria cultural.

Além disso, as discussões empreendidas por Butler contribuem com a consolidação das críticas ao feminismo de segunda onda, que, ao operar no marco heterossexual, branco e de um espaço privilegiado de classe, acabava por invisibilizar experiências marcadas por outros atravessamentos de diferença que engendravam opressões específicas, como nos casos das mulheres negras e mulheres transexuais (BARIL, 2007). É nesse sentido que Butler (1993, 1999, 2004) constantemente alertará em relação ao caráter excludente operado por qualquer categoria identitária, ainda que com finalidade de emancipação, como no caso da categoria mulheres no movimento feminista. Assim,

[...] feminism ought to be careful not to idealize certain expressions of gender that, in turn, produce new forms of hierarchy and exclusion. In particular, I opposed those regimes of truth that stipulated that certain kinds of gendered expressions were found to be false or derivative, and others, true and original. (BUTLER, 1999, p. VIII).

A partir dessa leitura é possível notar o paradoxo produzido no investimento na categoria política de mulheres enquanto sujeito do feminismo. Se, por um lado, essa demarcação é necessária para instituir a própria inteligibilidade do movimento, por outro, acaba por operar exclusões a partir de categorias que são sedimentadas, como as de sexo e gênero distintos e binários, bem como uma expressão de sexualidade específica, a heterossexual (ROSA, 2012). Ou seja, Butler defende em sua crítica à apropriação do conceito de gênero que a operação de segmentos do movimento feminista pode, ao naturalizar uma certa expressão dos gêneros, produzir um efeito diverso ao desejado inicialmente, qual seja, a superação da opressão das mulheres. Sobre a especificidade da leitura realizada por Butler, Baril (2007) afirma:

Cette philosophe croit donc qu'une certaine utilisation de la catégorie femmes engendre les effets contraires d'une libération. Elle soutient que les femmes sont les effets d'énoncés performatifs élaborés dans le cadre héterosexiste. Ainsi, le recours à de telles catégories identitaires est paradoxal puisqu'il a pour objet, d'une part, de libérer le groupe visé et, d'autre part, de l'enfermer, par le fait même, dans un cadre normatif rigide et qu'il passe ainsi sous silence le caractère factice et construit de cette catégorie (p. 69).

É essa interpretação crítica que permite a Butler articular de forma precisa o campo dos gêneros com a constituição, consolidação e manutenção de uma determinada organização política e cultural, de forma que "it becomes impossible to separate out 'gender' from the political and cultural intersections in which it is invariably produced and maintained" (BUTLER, 1999, p. 06). Nesse sentido, antes de qualquer possibilidade de naturalização do sistema de gênero binário, é defendido pela filósofa a artificialidade dos construtos de gênero que acabam, devido ao seu caráter repetitivo, naturalizando a relação entre uma determinada anatomia, ou sexo, e expressões de gênero e sexualidade específicas.

PAIVA, André Luiz dos Santos. Desontologização do sujeito generificado e a metafísica da substância: diálogos de Butler com Nietzsche. Griot : Revista de Filosofia, Amargosa - BA, v.22 n.1, p.130-143, fevereiro, 2022. 
Para Butler (1999), a ideia de um sistema de gênero que reflete diferenças sexuais naturais não se sustenta, uma vez ser o próprio processo de naturalização que impõe essa relação de mimetismo. Apesar de suas críticas em relação às perspectivas feministas que adotam para si esse pressuposto, não é possível definir o pensamento de Judith Butler como pós-feminista, dado sua crítica não ter a intenção de suplantar as teorias e políticas feministas, mas radicalizá-las através de uma crítica interna (BUTLER; TOHIDI, 2017). Esse aspecto permite também destacar o não abandono da própria categoria mulheres, mas apenas uma postura de uso estratégico dessa identidade para a ação política, mantendo o conceito aberto a ressignificações para que esse não opere processos de exclusão inviabilizadores da agência de sujeitos determinados (BARIL, 2007).

Essa compreensão e apropriação do feminismo, bem como do conceito de mulheres, relaciona-se com a própria concepção de identidade na teorização de Butler. Nesse sentido, o gênero seria um aspecto indissociável da constituição subjetiva em nossa cultura, sendo impossível pensar o gênero enquanto categoria pré ou pós-identitária, uma vez que os moldes de inteligibilidade possibilitadores do reconhecimento do sujeito enquanto humano passa, necessariamente, pela sua inclusão nas categorias de gênero disponíveis (BUTLER, 1999). Dessa forma, como defende Baril (2007), “pour Butler, la notion d'identité indépendante, non genrée, est absurde. L'identité est, selon elle, toujours déjà 'sexuée' sur le plan social, en ce sens qu'il n'est pas posible, dans le cadre dominant, de definir l'identité d'une personne sans que celle-ci soit genrée" (p. 73).

Essa relação intrínseca entre gênero e constituição identitária dos sujeitos é possível devido a não conexão entre produção de gênero e a pré-existência de um sujeito intencionado e consciente que elegeria seu gênero. Ou seja, o gênero, ainda que se tratando de um construto social específico fabricante das identidades, não pressupõe um agente prévio que o engendre, o que levaria a conclusão da existência de um sujeito anterior às categorias de gênero. Nesse sentido,

For if gender is constructed, it is not necessarily constructed by an "I" or a "we" who stands before that construction in any spatial or temporal sense of "before". Indeed, it is unclear that there can be an "I" or a "we" who has not been submitted, subjected to gender, where gendering is, among other things, the differentiating relations by which speaking subjects come into being. Subjected to gender, but subjectivated by gender, the "I" neither precedes nor follows the process of this gendering, but emerges only within and as the matrix of gender relations themselves (BUTLER, 1993, p. 07).

Essa matriz de gênero é uma das responsáveis pela delimitação do campo do humanamente inteligível, mantendo assim relações de coerência que culminam com a determinação linear e excludente entre sexo, gênero e sexualidade, numa dinâmica na qual o pertencimento a uma das categorias binárias pré-estabelecidas impossibilita a identificação com seu par, bem como determina os demais caracteres de sexo-gênero dos sujeitos (BUTLER, 1999).

É a partir da crítica a esse aspecto restritivo e excludente das identidades de sexo-gênero que Butler opera o questionamento do aspecto identitário como marco principal viabilizador da agência política dos indivíduos e coletivos. Essa crítica, no entanto, não advoga pelo abandono das identidades ou recusa de seu potencial para a transformação dos marcos sociais de inteligibilidade que regem as experiências humanas, uma vez que a unificação possibilitada pelo marco identitário potencializa a ação política. A filósofa propõe, a partir da subversão do próprio conceito de identidade, uma utilização aberta dos marcos identitários, com a finalidade de evitar uma imposição rígida excludente das experiências e grupos que não se adequem aos marcos normativos estabelecidos pelos movimentos de minorias, o que ocasionaria a produção de exclusões que imporiam uma postura antagônica à defendida pelos próprios movimentos.

PAIVA, André Luiz dos Santos. Desontologização do sujeito generificado e a metafísica da substância: diálogos de Butler com Nietzsche. Griot : Revista de Filosofia, Amargosa - BA, v.22 n.1, p.130-143, fevereiro, 2022. 
Butler reivindica a necessidade de uma desnaturalização das identidades sexuais e de gênero que permita o vislumbre dos gêneros não como realidades prévias aos sujeitos, mas como um campo normativo delimitador do próprio espaço que possibilita, ou não, a identificação dos sujeitos como humanos. As expressões de gênero seriam, assim, a postura em ato de uma cópia sem original que possibilitaria aos sujeitos seu ingresso no próprio campo normativo da cultura. Ou seja, não haveria uma verdade ontológica dos gêneros, mas uma construção artificial que, como principal ferramenta de consolidação, utilizaria o recurso à naturalização dessas expressões.

Ao questionar a pretensa naturalidade das expressões de gênero binárias, Butler conclui que "there is no gender identity behind the expressions of gender; that identity is performatively constituted by the very 'expressions' that are said to be its results" (BUTLER, 1999, p. 33). Torna-se, assim, impossível reivindicar uma verdade dos gêneros que se localize de forma anterior ao sujeito. Não haveria, dessa maneira, um gênero original a ser repetido através de atos performativos, mas a produção paródica da própria ideia de original baseada na pretensa naturalidade das expressões de gênero. É a partir desse pressuposto que Butler opera uma desontologização do sujeito generificado, o que possibilita pensar alternativas nos momentos de postura do gênero em ato que deixem em aberto o estatuto de veracidade ou falsidade dessas expressões, pois " genders can be neither true nor false, neither real nor apparent, neither original nor derived. As credible bearers of those attributes, however, genders can also be rendered thoroughly and radically incredible" (BUTLER, 1999, p. 180).

Dado o campo do gênero constituir-se como um espaço de produção da própria inteligibilidade humana, ao reivindicar possibilidades outras de expressões de gênero se defende, por consequência, a revisão do próprio conceito de humano. Ora, assim como os conceitos de homem e mulher, masculino e feminino, o conceito de humano sustenta-se a partir de generalizações que implicam a adesão a pressupostos assimilados como universais, naturais e inevitáveis (ROSA, 2012). No entanto, se o recurso à originalidade que justifica a reprodução de determinadas performances sociais é abandonado em detrimento de uma leitura que abdica da pretensão de estabelecimento de uma ontologia inevitável para a experiência humana, passa a ser possível pensar o campo do humanamente inteligível, assim como as expressões de gênero que o possibilitam, como marcos normativos passíveis de alteração.

O marco de inteligibilidade humana no âmbito das expressões de gênero passa, assim, a ser visto como um espaço de produção de hierarquias. Essa hierarquia é baseada na constituição da diferença sexual enquanto categoria natural para a consolidação do molde binário de gênero. É contra essa naturalização que opera a teoria de gênero desenvolvida por Butler, de forma que o caráter culturalmente construído das expressões de gênero é explicitado, bem como as relações políticas que sustentam essa hierarquia. Nesse sentido,

Butler insiste aussi sur le fait que le 'sexe', le genre, la sexualité, l'orientation sexualle et l'identité sexuelle ne partagent aucun lien structurel, nécessaire ou même métaphysique. Elle rappelle que ces divers éléments ont été juxtaposés culturellement afin de s'insérer dans une matrice de pouvoir hétéronormative et hétérosexiste (BARIL, 2007, p. 63).

Essa perspectiva permite, além de um questionamento teórico, o investimento num pensamento possibilitador da ação política, num sentido de propor a necessidade de revisão do campo normativo e simbólico que sustenta o sistema binário de gênero com a finalidade de ampliar o campo do humanamente inteligível. Assim, o ideal de gênero é questionado em sua pretensão de estabelecimento de uma ontologia teleológica para a consolidação das experiências humanas, abrindo espaço para a construção de outra ética de sexo-gênero, pautada na desnaturalização das experiências.

PAIVA, André Luiz dos Santos. Desontologização do sujeito generificado e a metafísica da substância: diálogos de Butler com Nietzsche. Griot : Revista de Filosofia, Amargosa - BA, v.22 n.1, p.130-143, fevereiro, 2022. 
Ao questionar o campo normativo de pretensões naturais, Butler explicita o embuste presente na instituição do essencialismo na definição dos gêneros. Nesse sentido, não haveria uma essência ou naturalidade dos gêneros, o que, por consequência, explicita o equívoco em pensar as expressões de sexo-gênero como estáveis e substanciais (BARIL, 2007). Com isso, pode-se notar duas formas de pensar as experiências de gênero, uma de pretensão natural e inflexível; e uma perspectiva crítica que defende a desontologização dessas experiências, distinção sobre a qual Butler (1999) afirma:

\begin{abstract}
We may be tempted to make the following distinction: a descriptive account of gender includes considerations of what makes gender intelligible, an inquiry into its conditions of possibility, whereas a normative account seeks to answer the question of which expressions of gender are acceptable, and which are not, supplying persuasive reasons to distinguish between such expressions in this way. The question, however, of what qualifies as "gender" is itself already a question that attests to a pervasively normative operation of power, a fugitive operation of "what will be the case" under the rubric of "what is the case." Thus, the very description of the field of gender is no sense prior to, or separable from, the question of its normative operation (P. XXI).
\end{abstract}

Esse vínculo entre as experiências de gênero e um determinado campo normativo permite a Butler pensá-las enquanto performativas. Nesse sentido, a ideia de performatividade ocupa o conceito anteriormente estabelecido enquanto identidade de gênero, num processo no qual o gênero deixa de ser entendido como algo que o sujeito é, para ser inserido no campo de uma prática que o sujeito faz e que o produz como sujeito (BUTLER, 1999; LLOYD, 1999).

A compreensão do gênero como um fazer performativo não inviabiliza pensar o sujeito, tampouco leva à sua negação. O que ocorre é uma mudança no foco analítico, dado o sujeito deixar de ter estatuto ontológico anterior aos seus atos de gênero (LLOYD, 1999). Ou seja, não há primeiro o sujeito que engendraria o gênero, mas um sujeito que se estabelece na própria fabricação dos gêneros através da performatividade. Esse movimento ocorre porque, a partir da perspectiva da performatividade de gênero, é a própria linguagem e discursos que possibilitam sua emergência, sendo esses anteriores aos sujeitos localizados e não o inverso disso (SALIH, 2012). Isso permite a Butler utilizar a performatividade como categoria filosófica (NAVARRO, 2008) que possibilita a desontologização da própria ideia de sujeito generificado através da crítica do conceito de diferença sexual.

\title{
Diferença sexual e a metafísica da substância
}

Ao questionar a categoria diferença sexual como constituinte inevitável das subjetividades, Butler (1993, 1999) desenvolve um conceito denominado de metafísica da substância. Essa metafísica seria responsável por instituir um paradigma naturalístico que impõe uma relação causal entre corpos, gêneros, sexualidade e desejo enquanto expressão genuína da subjetividade, ao invés de construtos sociais mantidos por coerções de variadas modalidades (BUTLER, 1999). Salih (2012) define esse conceito da seguinte maneira: "metafísica da substância' refere-se à crença difundida de que o sexo e corpo são entidades materiais, 'naturais', autoevidentes, ao passo que, para Butler, [...] sexo e gênero são construções culturais 'fantasmáticas' que demarcam e definem o corpo" (p. 72).

O que está em jogo no investimento nos aspectos culturais da diferença sexual no pensamento de Butler é o questionamento da própria distinção entre natureza e cultura. Nesse sentido, inclusive os modelos teóricos que explicam o gênero a partir da ideia desse ser a expressão da cultura que marca corpos, sendo esses bases ou receptáculos naturais, são questionados, pois a

PAIVA, André Luiz dos Santos. Desontologização do sujeito generificado e a metafísica da substância: diálogos de Butler com Nietzsche. Griot : Revista de Filosofia, Amargosa - BA, v.22 n.1, p.130-143, fevereiro, 2022. 
ideia da natureza como algo passivo que serviria de ponto de partida para a cultura contribui e adensa as demarcações excludentes nos campos dos gêneros e sexualidades, consolidando a metafísica da substância criticada pela autora (BUTLER, 1993).

Ao pensar a metafísica da substância, Butler desenvolve um aprofundamento acerca do tema da materialidade dos corpos, uma vez que a metafísica da substância é estabelecida quando se toma a corporeidade como ponto de partida inevitável para a justificação da diferença sexual. Nesse sentido, a filósofa busca compreender como a materialidade dos corpos, a qual ela não recusa, passou a ser imposta como algo irredutível ao invés de também construída do ponto de vista metafísico através de discursos e práticas específicas (BUTLER, 1993).

Ao se tomar o corpo como momento fundante da diferença sexual, ocorre a normatização das experiências num sentido dos momentos gênero e sexualidade que apareceriam como distintos, na verdade consolidam-se como meras continuidades dos marcadores corporais da diferença sexual, o que permite a Butler afirmar que

The unproblematic claim to "be" a woman and "be" heterosexual would be symptomatic of that metaphysics of gender substances. In the case of both "men" and "women," this claim tends to subordinate the notion of gender under that of identity and to lead to the conclusion that a person is a gender and is one in virtue of his or her sex, psychic sense of self, and various expressions of that psychic self, the most salient being that of sexual desire (BUTLER, 1999, p. 29).

Se expressa, assim, no pensamento de Butler, a constituição de um argumento que diz respeito ao campo da ontologia, uma vez que não seria possível à autora desenvolver suas teorizações acerca das experiências generificadas sem deparar-se com a necessidade de repensar o próprio conceito de existência humana. Dessa forma, o que interessa a Butler é pensar os efeitos particulares dessa metafísica no mundo, numa dinâmica que legitima algumas expressões sexuais e de gênero, ao passo que lança outras à abjeção (LLYOD, 2007).

Butler denuncia a metafisica da substância justamente devido aos efeitos de violência e exclusão por ela possibilitados. Para a autora, não há propriedades naturais ou internas que sustentem a hierarquização ocasionada pela diferença sexual, mas dinâmicas culturais e políticas que o fazem, de forma a não haver justificação para que os corpos e expressões de gênero sejam pautados numa dinâmica binária. Jagger (2008) afirma que essa conclusão dialoga diretamente com a defesa realizada por Butler do gênero como performativo, de maneira que

Butler's notion of performance and performativity avoids metaphysical questions about the ontological status of sexual difference because it focuses on the way that sexual difference functions as ontological difference, in the contemporary epistemic/ontological regime (JAGGER, 2008, p. 762).

Essa incursão no campo da metafísica e epistemologia em Butler tem grande influência do pensamento de Nietzsche, notadamente no que se refere às discussões empreendidas por esse autor em sua Genealogia da moral (NIETZSCHE, 2013). Nessa obra, Nietzsche busca traçar as origens dos conceitos de bem e mal, bom e mau partindo de algumas questões:

[...] de que modo inventou o homem estas apreciações de valor: o bem e o mal? E que valor têm em si mesmas? Foram ou não favoráveis ao desenvolvimento da humanidade? São um sintoma funesto do empobrecimento vital, de degeneração? Ou indicam, pelo contrário, plenitude, força e vontade de viver, coragem, confiança no futuro da vida? (NIETZSCHE, 2013, p. 25) 
Em seu percurso para responder tais perguntas, o filósofo parte de uma postura de desconfiança em relação à pretensa verdade dos conceitos por ele analisados. É dessa forma que Nietzsche (2013) defende a necessidade do estabelecimento da crítica frente aos valores morais a partir do conhecimento das condições e contextos nos quais esses surgiram e desenvolveram-se enquanto postulados. A partir de sua genealogia, Nietzsche denuncia a arbitrariedade do estabelecimento dos valores morais, de forma que não haveria uma verdade por trás dos conceitos, mas um ato, sendo esse o ato de inventar, fabricar as bases para uma moralidade. É nesse sentido que ele afirma que há uma oficina de fabricação de ideias, e essa, para ele, cheira "a mentira e a embuste" (NIETZSCHE, 2013, p. 50).

O caráter mentiroso dessa criação, em Nietzsche (2013), explica-se pela moralidade hegemônica de origem cristã ter como pressuposto a reificação da valorização do sofrimento e do castigo, característica por ele denominada de moral escrava, na qual os servos em suas insatisfações com os atos dos senhores criam uma moral de valorização do oposto ao que esses praticavam. No entanto, esse momento de invenção é ocultado, levando os humanos a acreditar que os valores por eles seguidos são os únicos ou, ao menos, os melhores possíveis.

Para Nietzsche (2013), “com a ajuda de tais invenções, conseguiu a vida justificar seu próprio 'mal'; talvez hoje precisássemos de outras invenções, por exemplo, considerar a vida como enigma, como um problema do conhecimento" (p. 67), o que explicita a intenção do autor de não apenas identificar o funcionamento de uma determinada moral, mas também questioná-la. Sendo o humano um ser que mede, aprecia e avalia valores, seria necessário, assim, reinventá-los com a finalidade de produção de uma experiência de vida não pautada na moralidade escrava valorizadora da crueldade e do castigo.

Evidentemente que essa alteração dos valores não é afirmada como sendo uma tarefa fácil, uma vez que o questionamento dos padrões morais baseados no binarismo entre bem e mal como categorias antagônicas e excludentes é um ataque à própria crença humana em relação a existência de uma verdade. Nesse sentido, todos que não se adequam a essa moralidade são vistos como devedores em relação aos imperativos morais e, assim, culpados:

O culpado é um devedor que não só não paga as vantagens obtidas, as suas dívidas, como
também ataca ao credor: a partir desse momento não só se priva de todos estes bens e
vantagens, como também será lembrada a importância desses bens. A cólera do credor,
isto é, da comunidade ofendida, constitui-o outra vez ao estado selvagem, põe-no fora da
lei, recusa-lhe a proteção e contra ele pode já cometer-se qualquer ato de hostilidade
(NIETZSCHE, 2013, p. 70).

Esse ataque que desperta cólera é, em Nietzsche, intencional. Assim, antes de questionar a validade dos valores morais, o filósofo realiza o questionamento da própria ideia de verdade que subjaz à defesa da moral. Em outro momento de sua obra (NIETZSCHE, 2011) ele já havia feito referência ao que denomina de pathos da verdade. Nele, a partir da capacidade humana do esquecimento, imagina-se ser a verdade algo que se possui como categoria irrefutável, e isso inviabiliza o vislumbre da verdade enquanto "cascas vazias" (NIETZSCHE, 2011, p. 10) e possibilita a defesa da verdade como categoria estável e independente da criação humana.

Essa opção pelo "esquecimento" do caráter construído da verdade dá-se devido a necessidade humana de viver em sociedade, ou no rebanho, como denomina Nietzsche (2011, 2013). Para isso ocorrer, é necessário o estabelecimento de um acordo de paz que passa necessariamente pelo estabelecimento das verdades como parâmetros estáveis e, por isso, apresentados enquanto absolutos, pois 
[...] na medida em que o homem, ao mesmo tempo por necessidade e por tédio, quer viver em sociedade e no rebanho, necessário lhe é concluir a paz e, de acordo com este tratado, fazer de modo tal que pelo menos o aspecto mais brutal do bellum omnium contra omnes desapareça do seu mundo. Ora, este tratado de paz fornece algo como um primeiro passo em vista de tal enigmático instinto de verdade. De fato, aquilo que daqui em diante deve ser a "verdade" é então fixado, quer dizer, é descoberta uma designação uniformemente válida e obrigatória das coisas, e a legislação da linguagem vai agora fornecer também as primeiras leis da verdade, pois, nesta ocasião e pela primeira vez, aparece uma oposição entre verdade e mentira (NIETZSCHE, 2011, p. 09-10).

Depreende-se disso que o desejo humano de estabelecimento da verdade relaciona-se com os resultados favoráveis possibilitados por ela, num sentido de facilitação da conservação da vida, o que leva Nietzsche (2011) à conclusão de que o conhecimento puro pouco importa na delimitação do conceito de verdade, pois está no centro da questão não o estatuto mesmo da verdade, mas os benefícios por ela trazidos, e isso justifica a postura hostil em relação às verdades com potencial destrutivo.

Configura-se nesse cenário uma versão realista da verdade que estabelece as crenças humanas como aquilo que reflete de forma adequada a realidade. Para isso se sustentar, se recorrerá, assim, a uma pretensa objetividade em relação à verdade, defendida como independente do humano, que por seu turno entra em contato com as verdades do mundo através de uma postura desinteressada e, por isso, neutra. O pathos da verdade, assim, consolida-se instituindo a verdade como algo pré-existente em relação ao humano, ao invés da ideia dela mesma ser constituída através da experiência humana (GEMES, 1992).

Esse mecanismo de produção é ocultado e, a partir de operações de simplificação, o humano pode criar um mundo inteligível e gerível por ele a partir de sistemas de verdadeiro ou falso (GEMES, 1992). No entanto, Nietzsche $(2011,2013)$ chama a atenção ao inverso desse pressuposto e denuncia que, para construção e manutenção dessa ordem de coisas, é possível perceber um grande relativismo em torno do que se pode considerar verdade. Para isso ele irá recorrer, principalmente, ao conceito de metáfora como explicativo da formação do conceito de verdade. Nesse sentido, o filósofo expõe:

O que é portanto a verdade? Uma multidão móvel de metáforas, metonímias e antropomorfismos; em resumo, uma soma de relações humanas que foram realçadas, transpostas e ornamentadas pela poesia e pela retórica e que, depois de um longo uso, pareceram estáveis, canônicas e obrigatórias aos olhos de um povo: as verdades são ilusões das quais se esqueceu que são, metáforas gastas que perderam a sua força sensível, moeda que perdeu sua efígie e que não é considerada mais como tal, mas apenas como metal (NIETZSCHE, 2011, p. 12-3).

Nietzsche refuta, assim, a noção de verdade incondicional e, portanto, válida em qualquer tempo (GEMES, 1992). É devido a isso que Glenn (2004) afirma que "the central idea in Nietzsche's view of reality is that everything is fluid, in motion. To put it in philosophical terms, the nature of the world is becoming, not being" (p. 576), ou seja, em Nietzsche encontramos a ideia dos conceitos como sendo, antes de verdades, imposições artificiais à realidade. Nesse sentido, ocorre um processo de antropoformização da realidade através da criação de ideias e leis pretensamente naturais e invariáveis (GLENN, 2004).

Ao se falar sobre as coisas da realidade humana, acredita-se no mais das vezes se possuir ou que seja possível possuir um saber sobre as coisas propriamente. No entanto, Nietzsche (2011) insiste que essas conclusões não passam de metáforas sem relação necessária e direta com as coisas. Apesar dessa dinâmica metafórica e arbitrária, o que permite a manutenção na crença na ideia da

PAIVA, André Luiz dos Santos. Desontologização do sujeito generificado e a metafísica da substância: diálogos de Butler com Nietzsche. Griot : Revista de Filosofia, Amargosa - BA, v.22 n.1, p.130-143, fevereiro, 2022. 
verdade das coisas e dos conceitos é a repetição compartilhada das metáforas. Nesse sentido, Nietzsche (2011) afirma ocorrer uma produção de mentiras dentro de uma dinâmica de convenção, denominada por ele de mentira de rebanho, que obriga os indivíduos a não apenas mentir, mas esquecer a origem criada das verdades, essas passando a ser defendidas como realidades absolutas e fechadas em si mesmas.

A mentira, devido ao esquecimento, ocorre então de forma inconsciente, a partir dos costumes que se perdem no tempo. Isso permite a instalação do sentimento de verdade em relação às criações humanas (NIETZSCHE, 2011). Esta fábula construída pelo filósofo acerca da verdade nos leva à tese central de sua incursão: o conhecimento humano deve ser analisado a partir de uma perspectiva relativa, o que pressupõe o abandono de qualquer recurso conceitual que parta de uma ideia de absoluto, pois,

Todo conceito surge da postulação da identidade do não-idêntico. Assim como é evidente que uma folha não é nunca completamente idêntica à outra, é também bastante evidente que o conceito de folha foi formado a partir do abandono arbitrário destas características particulares e do esquecimento daquilo que diferencia um objeto de outro. $\mathrm{O}$ conceito faz nascer a idéia de que haveria na natureza, independentemente das folhas particulares, algo como a "folha", algo como uma forma primordial, segundo a qual todas as folhas teriam sido tecidas, desenhadas, cortadas, coloridas, pregueadas, pintadas, mas por mãos tão inábeis que nenhum exemplar teria saído tão adequado ou fiel, de modo a ser uma cópia em conformidade com o original (NIETZSCHE, 2011, p. 12).

A partir dessas ideias de Nietzsche fica explícito que esse processo não ocorre apenas na vida cotidiana e não refletida. A filosofia e as ciências operariam da mesma maneira, dizendo verdades que são desde sempre metáforas, através de abstrações esquecidas enquanto tais. Estando o filósofo e o cientista também imersos na vida de rebanho, acabam por replicar em suas áreas os aspectos que contribuem para a manutenção da paz no rebanho, pautando a ideia de verdade muito mais num aspecto moral. Nesse sentido, a verdade passa a ser a facilitadora da vida em rebanho, e a mentira aquilo que a ameaça (SOBRINHO, 2011, p. 06).

Associam-se, assim, epistemologia e moral, numa dinâmica que replicará no âmbito da construção dos saberes os conflitos encontrados entre o forte e o fraco no campo moral. Isso leva à necessidade de pensar a questão da verdade como algo relacionado à política, uma vez que diz respeito às lutas acerca do poder. Nesse sentido, a epistemologia não pode ser pensada como o estudo objetivo da forma que conhecemos as coisas, mas como um campo relacionado a escolhas também morais que operam, em muitos dos casos, divisões dicotômicas acerca da realidade, baseadas, principalmente, na distinção entre o falso e o verdadeiro (GLENN, 2004).

A operação dessa dicotomia, esquecida como tal, ocorre devido ao desejo humano de dominar o mundo, o que leva à criação dos conceitos. Assim, devido a sua utilidade na manutenção da vida em rebanho, os conceitos humanos tornam-se uma espécie de segunda natureza, num processo que impõe um marco epistemológico a partir da expressão da fraqueza como a mais pura verdade. A principal expressão dessa dinâmica é notada na insistência do estabelecimento de um pensamento binário acerca da realidade e das variadas experiências humanas. Nesse contexto, a maior parte das pessoas entra em contato com o mundo a partir de uma leitura bifurcada do mundo (GLENN, 2004), na qual verdade e moral entrelaçam-se, uma vez que o considerado verdadeiro confunde-se com o que se considera bom. Isso leva ao ocultamente da própria complexidade da experiência do mundo, pois tudo com o que se estabelece contato deve enquadrar-se nas duas categorias prévias disponíveis, movimento possibilitado pela postura de não questionamento acerca da fabricação das categorias.

PAIVA, André Luiz dos Santos. Desontologização do sujeito generificado e a metafísica da substância: diálogos de Butler com Nietzsche. Griot : Revista de Filosofia, Amargosa - BA, v.22 n.1, p.130-143, fevereiro, 2022. 
Nietzsche (2011) defende não haver nada mais distante da certeza que essa maneira de operar acerca das coisas, que ignora o arbitrário de sua própria fabricação: "Classificamos as coisas segundo os gêneros, designamos l'arbre como masculino e a planta como feminino: que transposições arbitrárias! A que ponto estamos afastados do cânone da certeza" (p. 10). Essas classificações devem ser superadas para o pensamento do filósofo, que a partir dos conceitos existentes parte em direção ao seu questionamento e fabricação de outras possibilidades. É nesse sentido que Nietzsche utiliza as ideias como armas, e estas, antes de descrever a realidade, a constroem (GEMES, 1992), pois, para ele,

Esta armadura e este chão gigantesco dos conceitos, aos quais o homem necessitado se agarra durante a vida para assim se salvar, não é para o intelecto liberado senão um andaime e um joguete para suas obras de arte mais audaciosas; e quando ele o quebra, o parte em pedaços e o reconstrói juntando ironicamente as peças mais disparatadas e separando as peças que se encaixam melhor, isto revela que ele não precisa mais daquele expediente da indigência e que não se encontra mais guiado pelos conceitos, mas pelas intuições (NIETZSCHE, 2011, p. 20).

Encontraremos essa vocação também em Judith Butler, pois, partindo da crítica às substâncias em Nietzsche, ela opera a politização dos conceitos demarcadores da constituição da diferença sexual como um de seus objetivos teóricos. Para ela, existem razões políticas para a substancialização dos gêneros numa perspectiva binária (BUTLER, 1999), partindo desse pressuposto para a crítica à uma ontologia do gênero que naturaliza as ideias e opressões a elas relacionadas.

As categorias homem e mulher, sustentadoras da ontologia da diferença sexual, funcionam a partir de uma relação de anterioridade ofuscada das mesmas, uma vez que apesar de preexistirem aos sujeitos, são afirmadas como emergentes no momento de surgimento de cada um dos corpos sexuados. Nesse processo, a natureza imporia sua lei que demarcaria a necessária partição binária dos sexos e dos gêneros, sem a menção a qualquer tipo de constrangimento ou mecanismo de poder que a sustente (RODRÍGUEZ, 2002). Esse processo possibilita um senso de estabilidade nas experiências dos corpos e dos gêneros que apresentariam uma coerência necessária principalmente em relação a uma continuidade entre genitália e gênero, e, ainda depois, desses com um exercício específico de sexualidade (JAGGER, 2008).

No entanto, essa ontologia do gênero estável (LLOYD, 1999), a partir da perspectiva performativa da fabricação dos corpos e dos gêneros defendida por Butler (1999; 1993), passa a ser questionada devido ao seu caráter de estabilização excludente no que tange aos tipos de identidade possibilitadoras de uma existência propriamente humana, que, para serem mantidos, necessitam da produção e reprodução dos corpos a partir de atos performativos. Para a filósofa, "Nature' and the domain of materiality are ideas, ideological constructs, produced by these social institutions to support the political interests of the heterosexual contract" (BUTLER, 1999, p. 159).

A autora recorre, assim, ao conceito de ontologia, para questioná-lo. Em sua teoria de gênero, a ontologia é pensada a partir da repetição de discursos e atos que constrangem a uma forma habitual e, por isso naturalizada, das vivências dos corpos e gêneros. Nesse sentido, produzse a abjeção das experiências que, ainda que expressas na realidade, não respondem propriamente à ordem simbólica instituída (BUTLER, 1999), configurando-se, assim, como não vivíveis (DIAZ, 2012).

Deve-se, dessa forma, historicizar essas categorias e a construção dos discursos que as defendem como naturais e, por isso, imodificáveis. Nesse sentido, é necessário interrogar as 
ontologias como o que revela fundamentalmente a verdade das subjetividades e passar a vê-las como contingenciais e produtoras de efeitos de verdade, num processo de recusa de seu caráter neutro e objetivo, insistindo, assim, no caráter político de suas fabricações (LLOYD, 1999).

É a partir dessa perspectiva que Butler $(1999,1993)$ denuncia o caráter performativo da construção não apenas dos gêneros, mas também dos corpos, no sentido de serem os atos e signos que atravessam os corpos responsáveis pelas demarcações da inteligibilidade de gênero. Assim, não seria possível pensar numa substância anterior à linguagem e à cultura sobre a qual os signos seriam construídos, pois

If the notion of an abiding substance is a fictive construction produced through the compulsory ordering of attributes into coherent gender sequences, then it seems that gender as substance, the viability of man and woman as nouns, is called into question by the dissonant play of attributes that fail to conform to sequential or causal models of intelligibility (BUTLER, 1999, p. 32).

É nessa altura de seu pensamento que Butler, assim como Nietzsche e o utilizando como referência, interessa-se pelos aspectos epistemológicos envolvidos na construção da metafísica da substância que impõe a diferença sexual como demarcador das diferenças de gênero. Nesse sentido, a autora questiona os marcos através dos quais se percebe as subjetividades no que tange aos aspectos dos gêneros e corpos, propondo que esses não podem ser acessados ou conhecidos como entidades ontológicas fixas e prévias ao discurso que os engendram. Isso ocorre devido ao fato de que "any attempt to think, talk or write about it, as she sees it, therefore, requires the use of language. As a consequence, all knowledge and understanding of the body is linguistically mediated" (LLOYD, 2007, p. 2162).

A mediação da linguagem permite a Butler analisar as enunciações de caráter ontológico não a partir dos marcos da verdade ou falsidade, mas como um campo enunciativo que devido ao seu caráter construído pode ser questionado e, consequentemente, reformulado numa direção oposta à metafísica dominante (DIAZ, 2012). Assim, o pertencer ou não a um gênero não possuem em Butler nenhum caráter ontológico ou metafísico absoluto, sendo necessário rever os parâmetros instituídos que engendram violências sobre uma série de experiências divergentes dos padrões normativos naturalizados. Essa concepção acaba pondo em xeque uma série de categorias binárias sustentadas pelas epistemologias hegemônicas, bem como por perspectivas ontológicas que, pretendendo-se detentoras dos parâmetros de verdade acerca dos corpos e dos gêneros, acabam apenas por referendar uma estrutura normativa excludente.

A partir dessa dinâmica de ausência de uma ontologia fixa e imutável anterior à própria cultura, Butler consolidará sua crítica às perspectivas políticas e epistemológicas identitárias naturalizantes, que, via de regra, recorrem à metafísica da substância para legitimação de suas categorizações excludentes e, no mais das vezes, binárias. Para a filósofa,

Clearly, identities can appear as so many inert substantives; indeed, epistemological models tend to take this appearance as their point of theoretical departure. However, the substantive "I" only appears as such through a signifying practice that seeks to conceal its own workings and to naturalize its effects. Further, to qualify as a substantive identity is an arduous task, for such appearances are rule-generated identities, ones which rely on the consistent and repeated invocation of rules that condition and restrict culturally intelligible practices of identity (BUTLER, 1999, p. 184).

Em relação aos processos de naturalização, a questão dos corpos emerge como central, pois, devido à sua inegável realidade material, acabam por ser estabelecidos como ponto de partida

PAIVA, André Luiz dos Santos. Desontologização do sujeito generificado e a metafísica da substância: diálogos de Butler com Nietzsche. Griot : Revista de Filosofia, Amargosa - BA, v.22 n.1, p.130-143, fevereiro, 2022. 
para pensar as diferenças de sexo-gênero. É por essa razão que Butler (1993) privilegia as discussões em torno do corpo. Nesse sentido, a autora rejeita a dicotomia entre mente e corpo e analisa do ponto de vista teórico e político a incidência dos discursos na constituição dos corpos generificados, de forma a explicitar as relações entre sexo e gênero como constituintes das subjetividades a partir de uma matriz binária que encontra nas diferenças entre as genitálias a justificativa para a partição binária dos gêneros (CHAMBERS, 2007).

No entanto, longe de confundir a materialidade do corpo com os discursos que estabelecem sua realidade, Butler propõe ser a própria condição material do corpo que ganha sentido dentro de um marco discursivo específico. Assim, não haveria o corpo como categoria irredutível a partir do qual seria possível afirmar a verdade dos sexos, mas desde sempre discursos acerca da realidade material dos corpos que os dividem através de um esquema binário e, por isso, excludente, e a partir dessa divisão se estabelece a ontologia dos gêneros atrelados sempre aos corpos e, mais especificamente, às genitálias.

A questão da materialidade dos corpos deixa assim de ser, na filósofa, uma questão estritamente natural para ser pensada no marco de uma materialização, dado até mesmo o conceito do que se entende como matéria necessariamente passar pelo crivo da linguagem e da cultura. "In this sense, to know the significance of something is to know how and why it matters, where "to matter" means at once "to materialize' and 'to mean" (BUTLER, 1993, p. 32). A defesa realizada por Butler diz respeito à impossibilidade de pensar a materialidade dos corpos fora da linguagem, num processo que primaria pela realidade ontológica da diferença sexual como ponto de partida para a consolidação das diferenças de gênero. Assim, para Butler (1993),

To posit a materiality outside of language, where that materiality is considered ontologically distinct from language, is to undermine the possibility that language might be able to indicate or correspond to that domain of radical alterity. Hence the absolute distinction between language and materiality which was to secure the referential function of language undermines that function radically (p. 68).

Nesse sentido, mais do que a busca por uma base irredutível para o estabelecimento da diferença sexual, Butler propõe a problematização do próprio conceito de materialidade e, consequentemente, da matriz de sexo-gênero binária. Isso ocorre devido a defesa realizada por ela acerca da constituição histórico-cultural dessa matriz, num sentido no qual se torna impossível conceituar a própria materialidade dos corpos fora dos discursos hegemônicos acerca do sexo e dos gêneros (MARTÍNEZ, 2015).

Depreende-se disso a reiteração da ideia do caráter performativo da linguagem, inclusive quando se trata de algo com inegável realidade material como o corpo. No entanto, essa materialidade só ganha sentido dentro da cultura, não havendo, por isso, a possibilidade de se pensar qualquer ontologia dos corpos baseada em dados que se pretendam prévios à linguagem. No entanto, a partir disso não é possível afirmar haver em Butler a redução da materialidade dos corpos à linguagem, mas apenas uma conexão necessária e insuperável entre esses dois aspectos. Assim, falar em materialidade da linguagem ou de uma linguagem performativa que dá estatuto de realidade à matéria não é estabelecer uma indistinção entre elas. Em não havendo oposição entre materialidade e linguagem, como pretendem defender os discursos que impõem a diferença sexual como uma realidade inegável por prévia a qualquer imersão na linguagem e na cultura, não é tampouco possível afirmar, por oposição, que matéria e linguagem tratam-se da mesma coisa. As dinâmicas estabelecidas entre esses fatores são constantes. Em Butler, eles estão sempre se encontrando e colocando-se ao mesmo tempo além e aquém um do outro. Sendo isso que permite à autora afirmar que

PAIVA, André Luiz dos Santos. Desontologização do sujeito generificado e a metafísica da substância: diálogos de Butler com Nietzsche. Griot : Revista de Filosofia, Amargosa - BA, v.22 n.1, p.130-143, fevereiro, 2022. 
Language and materiality are fully embedded in each other, chiasmic in their interdependence but never fully collapsed into one another, i.e., reduced to one another, and yet neither fully ever exceeds the other. Always already implicated in each other, always already exceeding one another, language and materiality are never fully identical nor fully different (BUTLER, 1993, p. 69).

\section{Considerações finais}

A maneira de Butler vislumbrar as relações entre corpo e linguagem permite questionar a crença ontológica acerca das pretensas essências dos gêneros baseadas na diferença sexual (ROSA, 2012). A partir dessa concepção, pode-se falar, então, de processos de materialização dos corpos atravessados pela linguagem, de forma que o corpo institui-se como instância de inteligibilidade humana através não de uma força ontológica, mas de um jogo de ideias acerca dos corpos que possibilitam a constituição de um marco específico (LLOYD, 2007).

Essa perspectiva performativa para a análise dos processos de materialização dos corpos permite a Butler (1993) questionar os marcos normativos da diferença sexual que estabelecem uma leitura binária da experiência humana no âmbito do gênero. A partir disso, a autora refuta qualquer pretensão de se pensar os corpos como uma esfera ontológica e, por isso, pré-discursiva e pré-política, apontando assim para uma agenda nos campos ético e cultural possibilitadoras da defesa do pluralismo (CHAMBERS, 2007).

O corpo emerge, em Butler, não como instância justificadora de delimitações das experiências humanas, nem mesmo no que se refere à sua instituição como ponto de partida único para a ação política. Para a filósofa, os corpos importam não por trazerem consigo uma verdade basilar das subjetividades, mas por instituírem-se como vulneráveis justamente devido a emergência de um marco regulador excludente binário (CHAMBERS, 2007). A partir desse marco, institui-se o outro radical que, por isso, passa a ser pensado como uma impossibilidade e, assim, passível de eliminação.

Esse processo impõe uma necessária relação de disputa em torno da definição de uma vida propriamente humana, conceito sob o qual a matriz de sexo-gênero, baseada na ideia de diferença sexual, não torna possível o ingresso de experiências disparatadas de seus moldes, sendo isso que leva a pensadora a questionar a formação de dinâmicas de distribuição desigual dos poderes no campo das experiências sexuais e de gênero, para isso utilizando-se de arcabouços conceituais críticos como os empreendidos por Nietzsche. 


\section{Referências}

BARIL, Audrey. De la construction du genre à la construction du "sexe": les thèses féministes postmodernes dans l'oeuvre de Judith Butler. Recherches féministes, Vol. 20, N. 2, p. 61-90, 2007. BUTLER, Judith. Bodies that matter, on the discursive limits of "sex". Nova Iorque, Londres: Routledge, 1993.

BUTLER, Judith. Gender trouble: feminism and the subversion of identity. $2^{\mathrm{a}}$ ed. New York, London: Roudedge, 1999.

BUTLER, Judith. Undoing gender. New York, London: Roudedge, 2004.

BUTLER, Judith; TOHIDI, Nayereh. An interview on feminist ethics and theory with Judith Butler. Journal of Middle East Women's Studies, Vol. 13, N. 3, p. 461-468, 2017.

CHAMBERS, Samuel A. 'Sex' and the Problem of the Body: Reconstructing Judith Butler's Theory of Sex/Gender. Body \& Society, Vol.13, N.4, p. 47-75, 2007.

DIAZ, Elvira Burgos. Desconstrucción y subversión. In: SOLEY-BELTRAN, Patrícia; SABSAY, Leticia. Judith Butler en disputa: lecturas sobre la performatividad. Barcelona: Editorial Egales, 2012, p. 1180-1572 (Arquivo Kindle).

GEMES, Ken. Nietzsche's Critique of Truth. Philosophy and Phenomenological Research, Vol. 52, N.1, p. 47-65, 1992.

GLENN, Paul F. The Politics of Truth: Power in Nietzsche's Epistemology. Political Research Quarterly, Vol. 57, N. 4, p. 575-583, 2004.

JAGGER, Gill. Judith Butler: sexual politics, social change and the power of the performative. Londres e Nova Iorque: Routledge, 2008 (Arquivo Kindle).

LLOYD, Moya. Performativity, parody, politics. Theory, Culture \& Society, Vol. 16, N. 2, p. 195$213,1999$.

MARTÍNEZ, Ariel. La tensión entre materialidad y discurso: la mirada de Judith Butler sobre e 1 cuerpo. Cinta moebio, Vol.54, p. 325-335, 2015.

NAVARRO, Pablo Pérez. Del texto al sexo: Judith Butler y la performatividad. Espanha: Editorial Egales, 2008 (Arquivo Kindle).

NIETZSCHE, Friedrich. Verdade e mentira no sentido extramoral. Comum, Vol.6, N. 17, p. 05$23,2001$.

NIETZSCHE, Friedrich. A genealogia da moral. 4a ed. Petrópolis: Vozes, 2013.

RODRÍGUEZ, Eva Patricia Gil. ¿Por qué le llaman género cuando quieren decir sexo?: Una aproximación a la teoría de la performatividad de Judith Butler. Athenea Digital, N.2, p. 30-41, 2002.

ROSA, Patricia. Gênero: performativo ou ontológico?. Peri, Vol. 4, N. 1, p. 46-56, 2012.

SALIH, Sara. Judith Butler e a teoria queer. Belo Horizonte: Autêntica, 2012.

SOBRINHO, Noéli Correia de Melo. Apresentação por Noéli Correia de Melo Sobrinho. In: NIETZSCHE, Friedrich. Verdade e mentira no sentido extramoral. Comum, Vol.6, N. 17, p. 05$07,2001$.

Autor(a) para correspondência / Corresponding author: André Luiz dos Santos Paiva. alz.paiva@gmail.com 